\title{
Energy Optimization Based on Big Data
}

\author{
Huan $\mathrm{Li}^{\text {a) }}$, Zhe $\mathrm{Xu}^{\text {b) }}$ and Xiangjiang $\mathrm{Wu}^{\mathrm{c})}$ \\ School of North China Electric Power University, North China Electric Power University, Baoding 071000, China. \\ a) 513719678@qq.com \\ b)@1064304905@qq.com \\ c)709726121@qq.com
}

\begin{abstract}
In this paper, a model is established to research the energy profile in the four states. The mainly work is the analysis on energy profile. After deleting the redundant data in the given table and supplying the missing data, we divide energy into several categories. Then, we take the sustainable energy development as the goal, adopting factor analysis model to get the weight vector. Then through the establishment of a comprehensive evaluation system, we get the energy profile order from superior to inferior: California (CA), Texas (TX), Arizona (AZ), New Mexico (NM) in 2009 according to the comprehensive index and the coupling degree. It is shown that the proposed model is feasible and robust. Besides, it provides new ideas for the rational allocation of regional energy.
\end{abstract}

Key words: LMDI; Multiple Regression Analysis; Factor Analysis; Time Series Analysis.

\section{INDEX SELECTION}

We take sustainable energy development as criteria which assess the "best" profile for use of cleaner, renewable energy in 2009.

Sustainable development of energy means that various kinds of energy are effectively exploited and utilized in the contemporary era. At the same time, it is able to create a development process for future generations to continuously utilize various energy conditions. Evaluation of the level of sustainable development of energy must from the evaluation of the current development and utilization of various energy sources and evaluation of the ongoing development and utilization of the sustainability of two. From another perspective, the ultimate goal of promoting sustainable energy development is to support social, economic and environmental sustainable development so as to eventually achieve harmony between man and nature. Therefore, when choosing the evaluation index, it is necessary to consider the relationship between energy and social, economic and environmental aspects.

We select six indicators from the efficiency of energy consumption, energy structure, industry development, energy market stability, environment five aspects. And in the choice of indicators to the relative indicators of the main, so as to reduce the size of the economy caused by the evaluation bias, a better reflection of the state sustainable development of energy levels.

TABLE 1. Evaluation index of energy sustainable development level.

\begin{tabular}{c|c}
\hline Topics & Evaluation Index \\
\hline The Efficiency of Energy Consumption & GDP Per Capita \\
Energy Structure & Total Energy Consumed Per Dollar of Real GDP \\
Energy Market Stability & Cleaner Resource Proportion \\
Environment & Renewable Resource Proportion \\
& Electric External Dependence \\
& Carbon Dioxide Emission \\
\hline
\end{tabular}




\section{FACTORS ANALYSIS}

In order to overcome the subjective factors such as expert scoring and fuzzy clustering, this paper uses principal component analysis and factor analysis to calculate the factor score. Before factor analysis, the raw data is first normalized and normalized. After calculating the contribution rate of variance, the software automatically extracts the first two principal components.

TABLE 2. Explain the total variance.

\begin{tabular}{|c|c|c|c|c|c|c|}
\hline \multirow{2}{*}{ Components } & \multicolumn{3}{|c|}{ Initial eigenvalue } & & \multicolumn{2}{|c|}{ Components } \\
\hline & Total & Variance $\%$ & Accumulation $\%$ & & 1 & 2 \\
\hline 1 & 3.382 & 56.361 & 56.361 & Percapita GDP & .717 & .680 \\
\hline 2 & 1.837 & 30.611 & 86.971 & renewable pro & .955 & $-3.321 \mathrm{E}-5$ \\
\hline 3 & 0.782 & 13.029 & 100.000 & clean_pro & .244 & -.691 \\
\hline 4 & $3.185 \mathrm{E}-16$ & $5.309 \mathrm{E}-15$ & 100.000 & unitGDPenergy & -.921 & .388 \\
\hline 5 & $-1.055 \mathrm{E}-16$ & $-1.759 \mathrm{E}-15$ & 100.000 & ex_dependence_power & .875 & .479 \\
\hline 6 & $-5.363 \mathrm{E}-16$ & $-8.939 E-15$ & 100.000 & CO2emissions & .205 & .870 \\
\hline
\end{tabular}

Generated rotational component matrix, component score coefficient matrix shows in Tab.3.

In the Tab.2 and Tab.3, the extracting method is both principal component analyses. And the rotation method is Kaiser-standardized orthogonal rotation method.

According to factor score coefficient matrix, combined with the variance contribution rate, the score of factor scores is obtained:

TABLE 4. Factors scores.

\begin{tabular}{ccccc}
\hline Rank & States & Factor1 & Factor2 & Total points \\
\hline 3 & AZ & 0.32531 & -0.37559 & -0.050285 \\
\hline 1 & CA & 1.0105 & -0.24828 & 0.76219 \\
\hline 4 & NM & -0.18126 & 0.016797 & -0.16446 \\
\hline 2 & TX & -0.14453 & 0.49932 & 0.35479
\end{tabular}

\section{EVALUATION SYSTEM}

\section{The Weight of the Indicator in Evaluation System}

Based on the results of the above SPSS analysis, we obtained the weight of each indicator $\mathrm{w}=(0.3629,0.2990,-$ $0.06315,-0.21027,0.3708$, and 0.2407 ). The process is as follows:

Obtain the coefficient of the index in the linear combination of different principal components. The square root of the corresponding eigenvalues is the number of loads in the rotation component matrix

Find the contribution rate of the variance of the principal components and take the weighted average of the coefficients in the linear combination of the two factors extracted according to the factor contribution rate.

Normalize indicator weight.

\section{Composite Index Calculation}

We consider Tier 1 indicators (energy efficiency, energy structure, energy market safety, and environment) as equally important. Therefore, the weight of each level is 0.25 . Accordingly, the quadratic indicators of the four 
subsystems are multiplied by their normalized values and summed, then multiply by 0.25 . That is the system of comprehensive development index. The larger the composite index, the higher the level of system development. The sum of the composite indices for each system gives the composite index for each state, indicating that the higher the level of state development, the better the economy is.

The results as Tab.5:

TABLE 5. Composite index for each state.

\begin{tabular}{cccccc}
\hline state & $\begin{array}{c}\text { The Efficiency of Energy } \\
\text { Consumption }\end{array}$ & $\begin{array}{c}\text { Energy } \\
\text { Structure }\end{array}$ & $\begin{array}{c}\text { Energy Market } \\
\text { Stability }\end{array}$ & Environment & Sum \\
\hline AZ & 0.078638 & 0.14117 & 0.22146 & 0.13571 & 0.5770 \\
CA & 0.28285 & 0.28849 & 0.41075 & 0.20712 & 1.1832 \\
NM & 0.0057358 & 0.14837 & 0.20783 & 0.12643 & 0.4861 \\
TX & 0.10217 & 0.12039 & 0.27235 & 0.25280 & 0.7477 \\
\hline
\end{tabular}

\section{Coupling Degree Calculation}

Based on the definition of the coupling model and the calculated composite index of each system, there are the following formulas.

$$
\begin{aligned}
& C=\frac{X Y Z K}{\left(\frac{X+Y+Z+K}{4}\right)^{4}} \\
& T=\alpha X+\beta Y+\gamma Z+\delta K
\end{aligned}
$$

And the degree of coupling of the ternary system can be calculated by Equation (3).

$$
D=\sqrt{C \times T}
$$

The closer $\mathrm{C}$ is to 1 , the higher the overall system coordination is. Where $(0 \leq C \leq 1)$

The calculation results are as follows:

TABLE 6. Coupling degree of four states.

\begin{tabular}{ccccc}
\multicolumn{7}{c}{ TABLE 6. Coupling degree of four states. } \\
\hline AZ & CA & NM & TX \\
\hline Coupling degree & 0.2126 & 0.5173 & 0.1102 & 0.3591 \\
\hline
\end{tabular}

\section{Judgment of System Coupling Type}

According to the relevant research, we set the coupling criterion:

TABLE 7. The coupling criterion.

\begin{tabular}{c|c}
\hline Coupling degree $(\mathrm{D})$ & Type \\
\hline $0.00 \sim 0.19$ & Decades of recession \\
$0.20 \sim 0.39$ & Primary coordinated development \\
$0.40 \sim 0.59$ & Intermediate level of coordinated development \\
$0.60 \sim 0.79$ & Good coordination of development \\
$0.80 \sim 1.00$ & High-quality and coordinated development \\
\hline
\end{tabular}

\section{CONCLUSION}

As can be seen from the composite index, CA is the most developed in the four states and the best in development, with the exception of the state of the environment, with the best energy efficiency in all other areas, 
while NM is the worst. Generally, from the perspective of the composite index, the four states rank in descending order of development is $\mathrm{CA}>\mathrm{TX}>\mathrm{AZ}>\mathrm{NM}$.

As for the perspective of coupling degree, according to coupling degree calculated and system coupling type, AZ belongs to primary coordinated development type, CA belongs to intermediate level of coordinated development, NM belongs to Decades of recession and TX belongs to Primary coordinated development. From the energy efficiency, energy structure, energy market security, environmental coupling degree, the four states rank is $\mathrm{CA}>\mathrm{TX}>\mathrm{AZ}>\mathrm{NM}$.

In summary, California has the best energy of sustainable development among the four states.

\section{REFERENCES}

1. Yang Hong-juan, LIU Hai-yang, LIU Hong-qin, An Analysis on Factors in Influencing Energy Consumption of Ethnic Minority Areas in Yunnan Province Based on LMDI Model [J], Journal of Kunming University of Science and Technology, 2015, 15(04): 51-58.

2. Liu Chang, LI Ji-cai, Research on Energy Consumption Evaluation and Optimization Based on LMDI - ANN DEA Integrated Method [J], Jianghuai Tribune, 2017, 284(4): 77-82.

3. Sun Xiao-ling, SHI Wei-dong, Establishment and analysis of evaluation model of sustainable development for regional energy in China [J], Resources \& Industries, 2008, 10(4): 16-23.

4. Zhang Can, Research on the Coordinated Development of Energy, Economy and Environment (3E) in Shandong Province [D], Qingdao University, 2016. 